Anna Trosborg

\title{
Strategies in Negotiation
}

\begin{abstract}
This paper outlines major strategies in negotiation and points to some difficulties nonnative speakers are likely to experience when taking part in commercial, international negotiations. It stresses the need for an approach which integrates social and psychological knowledge of the process and strategies of negotiation interactions with cross-cultural and cross-linguistic aspects, from which guidelines for the practical training of negotiators can be derived.
\end{abstract}

\section{Fig 1}

\section{Introduction}

The prevalence of negotiation described above has been emphasized by Kennedy/Benson/McMillan (1981,1).

For Danes negotiating in international contexts (commercial, diplomatic) efficient communication skills are essential (cf. Eksport og uddannelse, a document published by The Federation of Danish Industries (Industrirådet) in 1988). The vast majority of these international negotiations are conducted in a foreign language (most commonly English) and in depth knowledge of the foreign language, as well as mastery of effective negotiation tactics, are of decisive importance. This paper deals, in particular, with negotiation strategies and communicative problems in connection with successful realisation of these strategies, i.e. problems which are likely to face the Danish businessman negotiating abroad.

\subsection{Background}

The concept of communicative competence has played an important role in language teaching and learning during the past decade. Researchers have been engaged in developing and describing this concept and in outlining the components involved, while material writers have contri- 
buted with language teaching material constructed with the aim of teaching communicative functions. However, while this continuously increasing bulk of material has a lot to offer students at the lower and intermediate levels, there is still very little relevant material for the advanced student. For the businessman/woman who has to handle negotiations of decisive importance to his/her company, the knowledge to be gained through relevant research findings and teaching material is even scarcer.

Communicative competence has been defined in terms of the needs of the learner in everyday situations without regard to the specific needs of the more advanced learners. Although the communicative approach to language originated in Language for Specific Purposes (LSP), this very important part of communication has received little attention in the development and specification of communicative competence.

However, the influence of communicative competence on the field of language teaching has resulted in a new emphasis on the nature of interaction. This approach has led to the description of a great number of concepts and functions within pragmatics and discourse which are also highly relevant within the context of business communication.

An important task lies in adapting already existing knowledge within the field of communication theory to LSP, hand in hand with the development of new concepts of particular interest to this field. For example, what are the communicative needs of export managers, what types of interaction do they participate in, what are their roles, what kinds of communicative acts do they wish to perform, what particular technical terms do they need to know, etc.? A large number of problems await investigation, one of which is the adaptation of knowledge of communicative strategies to negotiation interactions.

\subsection{Definition of negotiation}

A negotiation involves a conflict. If there is a conflict with no solution at hand, the parties involved may decide to try to reach an agreement by means of a discussion. In the literature on negotiation a number of definitions have been offered (see, e.g. Wagner/Petersen 1988). The following definition presented by Lampi $(1986,9)$ captures the main aspects:

A negotiation is an interactive activity between at least two parties who have conflicting interests, at least one mutual problem, and who are in the process of looking for a solution to the problem(s) and/or resolving the conflict.

Lampi points out that the study of negotiation activities should focus 
on the two main aspects: interaction and phases/development in the problem/conflict (re)solving process.

\subsection{Commercial, international negotiations}

Commercial (as opposed to political and domestic) negotiations are defined by Kennedy/Benson/McMillan $(1983,117)$ as "all negotiations conducted in a non labour versus capital environment where monetary values are dominant". They point out that this definition excludes negotiations at the international level between governments on diplomatic or political matters, though it is often the case that commerce is an important part of these types of negotiations (e.g. inter-EEC member negotiations, trade deals, and negotiations of the funding of foreign currency transactions), as well as all negotiations at the domestic level where monetary transactions are excluded.

In the commercial environment, a company is free to choose its trading partner, and neither party is obliged to do business with the other. In contrast, in most negotiations in the industrial environment and in the political environment, the two parties must eventually come to an agreement.

Bilateral negotiations occur between a buyer and a seller who attempt to do business with each other. When two or more parties compete with each other to do business with a third party, we have trilateral competitive negotiations.

An examination of international (as opposed to domestic) negotiations reveals that an obvious cause adding to the complexity of international negotiations is differences in cultural heritage. In addition, negotiators have found it difficult to benefit from the available theoretical schemes, and, consequently, have been left to rely on their own intuition, flair and experience (Dupont 1988, 3). Lack of a common framework, as well as the difficulty involved in translating analytical theories into practical help to negotiators, are severe problems to be overcome as regards international negotiations.

Therefore, there is a need for "a systematic rigorous approach to negotiation" which can enable the negotiator to achieve a better understanding of the process and be helpful in determining a result from which useful knowledge and practical guidelines for purposeful action and appropriate behaviour can be derived.

\subsection{Model of negotiation}


A simple model of negotiation has been presented by Dupont (1988).

According to the model negotiation is seen as a complex interaction

Fig. 2

between two inextricably interrelated dimensions: contents and behaviour. Contents relate to issues, stakes, interests, and power (determined by the degree of interdependency between the parties). Behaviour, on the other hand, is seen as relating to individual, as well as cultural factors, it is determined by procedures (the sequence of moves by parties) and is expressed in face-to-face interaction involving communication modes and styles. In turn, behaviour is influenced by choice of strategies.

\subsection{Negotiation and culture}

By their very nature, international negotiations have a cross-cultural component. Numerous studies deal with cross-cultural communication, e.g. Brislin 1981, Samovar/Porter 1982, Harris/Moran 1983, Ricks 1983, to mention just a few. This does not mean, however, that there is a general consensus on what constitutes the hard core of culture, nor does it mean that there is a ready-made definition of the concept of culture. As pointed out by Kroeber and Kluckholm (1982), no less than 164 definitions of that term are to be found in the existing literature. See also Pilegaard (this volume) on this matter.

Nevertheless, the importance of cross-cultural understanding for the 
successful outcome of negotiations is generally recognized and a number of studies have been concerned with this aspect of negotiation. A study by Hoffstede (1980) reflects empirical research on the cross-cultural position of a Dutch technical-commercial negotiator, and Moran (1983) gives a detailed account of the numerous problems confronting any American negotiating with the Japanese. Kennedy (1985) concerns himself with aspects to be considered in connection with "the (Russian) comrades, the Japanese, the Arabs, the inscrutable Chinese, the European tribes, and the US negotiator". A Dutch research project on technical business negotiation in a cross-linguistic and cross-cultural setting is in progress (see Stalpers/Ulijn 1984, Ulijn/Gorter 1987). The project aims at making explicit the role of language and culture in international negotiations.

In addition, a recent approach to the connection between culture and behaviour (Janosik 1988) has pointed to the importance of getting beyond stereotypes in order to achieve in depth studies of social customs and usages related to negotiations.

Different cultures have produced different styles of negotiating. Graham/Herberger (1983) have pointed out how difficult Americans find it not to "shoot from the hip". They do not understand that when it comes to bargaining overseas, the Old West style of shooting first and asking questions later usually does not work. The lack of knowledge about other cultures is losing the Americans business overseas. Different emphasis is placed on status. While Americans tend to play down status to make their clients feel comfortable, in Far Eastern countries (Japan) great importance is attached to status. There are different attitudes to silence. The Japanese would use silence for the strategic purpose of avoiding a conflict, while in Western cultures silent periods are not tolerated (cf. the use of "fillers"). In Brazilian conversational style, bargainers often speak simultaneously, etc.

Even though a negotiator must be aware of the impact of cultural differences on the negotiation process, it is not always necessary to go all the way to bridge the gap between differences. Dupont (1988) suggests that the proper conduct is often half-way between the "when in Rome do as the Romans do" attitude and the opposite of simply "acting naturally". What the opposite party wants is respect and tolerance, they want to negotiate, i.e. to agree on some acceptable joint solution without which differing interests could not be reconciled despite the element of interdependence involved when seeking a solution to a conflict or undertaking a 
project.

Cultural differences are to be welcomed as a source of enrichment, a way to add up cultural strengths instead of letting differences be a divisive factor (ibid p. 15), and cultural adaptation and tolerance become basic requirements for international negotiators. Furthermore, as pointed out by Ulijn/Gorter (1987), for the experienced internationally minded negotiator negotiation often becomes more a person-to-person matter than a culture-to-culture matter.

Thus, although culture and its many methodological difficulties can by no means be neglected, it might be more manageable to start from the negotiation methodology as such looking at the process and strategies of negotiation and the various aspects and components involved. This would give an opportunity for deriving a comparative, multi-cultural analysis with more flexibility of approach.

\section{Process and strategies}

In addition to the cultural aspects of negotiation researched so far, economic and social-psychological aspects of the negotiation process have been in focus. Economic aspects of negotiation involve such factors as price and quality of the product, delivery and payment conditions, and after sales service (cf. Dupont 1989). Social-psychological aspects of the negotiation process have mainly been directed towards an investigation of behavioural factors such as negotiation strategies. Knowledge of successful negotiation tactics and strategies is crucial to managing international negotiations and this aspect is treated in some detail below.

When a specific strategy is described, the negotiator is most often directly addressed in order to disambiguate pronominal reference to the negotiator/the opponent.

\subsection{Situational background}

Negotiation is a complicated task. Several activities go on at the same time, e.g. talking, listening, thinking up arguments and giving explanations, formulating questions, as well as seeking an agreement. The difficulty of the task is further enlarged because most negotiations are undertaken in a situation that arises out of conflict. The negotiating parties operate from different starting points, have different aspiration levels and opposing desires for the outcome of an arranged meeting. The desired goal of the interaction conflicts with the social goal, and the interaction is likely to take place within an atmosphere of conflict. Because each party 
comes with expectations and goals to be obtained - the latter at the cost of the partner - the very obvious goal of reaching a solution, of coming to an agreement with your partner, is not very easy viewed within the conditions under which most negotiations are carried out. Pride and frustration (in cases where the goal is not achieved) are engaged to a much greater degree than in most everyday conversations.

As a speaker of a foreign language, one is at a disadvantage. Research has shown that conflict ridden language and negative reactions are particularly difficult to handle for the non-native speaker (cf. Trosborg 1987a). There is a tendency for most learners to revert to simplified and often tactless language almost instinctively when they find themselves in a situation of conflict, when met with opposition, accusations, etc.

\subsection{Stages in the process of negotiation}

Several attempts have been made to identify the stages involved in negotiation.

Wagner (1989) divides the act of negotiation into three phases: Die Vorbereitungsphase, die eigentliche Verhandlungsphase, and die Ratifikationsphase. The first phase in which the respective parties prepare the negotiation may involve internal negotiations within the firm, the second phase comprises argumentation about technical details, terms of delivery, etc., and during the third phase a contract is worked out. Wagner offers no detailed description of processes and strategies likely to be part of the second phase which constitutes the core phase of the negotiation. More detailed descriptions are to be found in earlier studies.

Based on the answers to the question: "what is discussed in a negotiation-meeting and in which order" derived from twenty buyers of a Dutch company (Stalpers/Ulijn 1984, 2), negotiation is, broadly speaking, thought to comprise the following phases and themes:

Lees (1984) has concerned himself with the actual process of negotia-

Fig. 3 
tion. In the illustration below (ibid. p. 12) he describes negotiation as a three-stage process:

1. Stating position, in extreme form - i.e. aspiration level

\section{Fig. 4}

2. Examining possibilities of cooperation

3. Moving together through mutual concessions

Agreement may be more favourable to one party (a1) or the other (a2), but the principle of exchange of concessions, equal in number though not necessarily in value, generally applies.

\subsection{Aspiration level}

A great problem lies in the attitude to aspiration level. Although most foreign executives expect to spend time negotiating and expect to make concessions, their aspiration levels may differ widely. Graham/Herberger (1983) point out that while, e.g. Americans tend to start bargaining at a price pretty close to what they want and expect to achieve, bargainers in many other countries leave themselves room to maneuver. To an Oriental or Latin American, for example, it makes perfect sense to ask for a lot initially, even though they are willing to move a lot. Americans and most West-Europeans, on the other hand, do not have the same expectations and are often upset by the other part's "unreasonable" demands.

Another related aspect is the negotiator's expectations concerning the information he/she gets. In Western societies honest information is expected, while in some other countries people have different attitudes and values about "honest" information. In Brazil, for example, being tricky is a less serious transgression of negotiation ethics (Graham/Herberger 1983, 163).

With respect to aspiration level, Kennedy/Benson/McMillan (1983) advise negotiators to "open realistically" and "move modestly". What is considered to be a realistic opening will depend a great deal on the circumstances of the negotiation and the environment normally associated with the type of negotiation you are engaged in (see e.g. Pye 1982, Kennedy 1985 , on cultural differences). It is important to try to analyse your 
opponent's style - is the opening a genuine position? Is his/her firmness merely due to genuine commitment? etc. Likewise, it pays to "educate" your opponent in your style of negotiating. Your opponent's expectations will be determined by your own negotiating behaviour, and it is important to act consistently. If you vary your style - sometimes open with a wide negotiating margin, sometimes with a narrow one - your opponent may misread the situation and assume the margin is wide when, in fact, it is narrow (cf. Kennedy/Benson/McMillan 1983, 68-73).

To achieve agreements you must be prepared to negotiate. Negotiators do not split the difference in aspiration level between them. Different agreements will result from different ways of managing negotiations, and what happens at the stages of, e.g. arguing, proposing, and bargaining greatly influences the final outcome.

\subsection{The importance of non-task sounding}

According to Graham/Herberger (1983, 163), business negotiations proceed in the following four stages: 1 . Non-task sounding, 2. Taskrelated exchange of information, 3. Persuasion, 4. Concessions and agreement.

The stage of non-task sounding, which has only been mentioned by Graham/Herberger (1983), involves all the activities that establish rapport but it does not include information related to the "business" of the meeting. The importance of establishing and maintaining personal contact is a controversial issue. In some countries this aspect is very important. The heart of the matter is not so much persuasion as getting to know the people involved. For example, the Brazilian way of doing business necessitates a long period of non-task sounding; much time is spent in developing a strong relationship of trust before business can begin. For Americans, in contrast, "the heart of the matter" is the persuasion stage (cf. Graham/Herberger 1983, 163).

While the time allotted to non-task sounding varies with respect to culture, the importance of being "a socially acceptable person" has been repeatedly stressed (see, e.g. Beneke's (1981) report of European executive managers' evaluation of their foreign language needs). In this respect "small talk" is important, and it is not necessarily restricted to an opening phase.

\subsection{The Eight-step Approach}


A more detailed approach has been presented by Kennedy/Benson/ McMillan (1981). Their approach to negotiation involves eight specific steps "common to all negotiations and appropriate to all combinations of personality", and they claim that their approach and the associated skills can be used to analyse most negotiations: "No matter what standpoint we took: buyer, seller, accountant, diplomat, hijacker, husband, wife or child, the Eight-step Approach was applicable" (p. 116).

The eight steps in question are the following:

1. preparing

2. arguing

3. signalling

4. proposing

5. packaging

6. bargaining

7. closing

8. agreeing

For a detailed description of these stages, the reader is referred to the authors' own work. In the following, I give only a brief description of the stages and take up aspects which are likely to present problems for the negotiator, especially if he/she is a non-native speaker.

\subsubsection{Preparing}

The initial step in the process of negotiation as distinguished by Kennedy/Benson/McMillan is that of preparing yourself for the negotiation proper. The strategies and tactics a negotiator intends to employ must be carefully considered; he/she must know what concessions can be made if necessary, the absolute limit, order of presentation of proposals, etc. Furthermore, it is necessary to try to identify your opponent's interests, e.g. in order to promote an agreeement and anticipate points of difficulty.

Preparing for the negotiation is a cognitive process. It is a thought process which takes place before and during the negotiation. This means that the language utilized in this process - if any - is only inwardly processed and cannot be assessed by the opponent or the analyst. Still, the importance of this stage cannot be stressed too much.

\subsubsection{Arguing}

The argument step is the opening where each side states his/her initial position, exchanges information, confers, etc. Each party will give reasons for his/her position, and seek to persuade the other party by reaso- 
ning. Thus this step comprises Graham/Herberger's second and third stages and might as well be divided into a stage of presentation and a stage of persuasion.

Emotional conflict, as well as rational presentation, is part of this stage. People negotiate because they have, or believe they have, a conflict of interests or rights with the other party. They are most aware of the conflict between themselves and the other party at the initial stages of the negotiations. Therefore, negotiations tend to be tense during this phase.

Argumentation must be constructive. Some negotiations do not get beyond the opening, but break down because inter-party tension is heightened by the behaviour of the parties towards each other. Instead of approaching each other the parties move further apart. The result is often a breakdown of the negotiation and the consequence may be a lost order. To avoid a breakdown, it is important to ask positive and open questions and avoid provocative language. From your preparation you know your own point of view and have made estimates about your opponent's. In the argument step you have the important task of testing those estimates. Questioning can give you access to all kinds of information about your opponent's objectives, his/her commitments and intentions, attitudes, and interests. When you have extracted information from your opponent you are in a better position to respond to his/her declared position and to explain your own.

Negative arguments, on the other hand, are likely to create a hostile atmosphere. This may hinder an open negotiation and even an agreement which is mutually advantageous.

What takes place at the argument step will greatly affect the progress, and the outcome, of the negotiations. Argumentation is not confined to the opening contact between the negotiators, but may recur over and over again during the negotiation.

\subsubsection{Signalling}

If a negotiation has come to a deadlock, the negotiators are faced with a very difficult situation, a dilemma which has only been discussed in Kennedy/Benson/McMillan (1984). They suggest that the negotiator who has come to a deadlock in argumentation but is still willing to find a solution can break out of the argument step by way of signalling.

Deadlock may be due to each party's adoption of a strategy whereby each maintain his/her opening position until the other party indicates a willingness to move. If both parties stick rigidly to this strategy there can 
be no movement. However, in negotiation parties must move towards each other, if the negotiation is to be successful - or one party can agree to move on one issue if the other party agrees to move on another issue. This movement can be achieved by signalling or responding positively to your opponent's signals.

A signal indicates that total opposition is confined to the present form of what has been proposed and implies that a proposition in another form would be negotiable.

However, many negotiators hesitate to make concessions for fear of surrendering to their opponent's point of view. Inability to handle concessions may come from a lack of experience. Kennedy/Benson/McMillan point out that novice negotiators are either "pushovers" or "stonewalls", they either throw everything away quickly or give nothing away at all. This way they either get poor deals or no deals, until they gain more experience $(1983,53)$.

Confident handling of concessions is obtained by developing skills in signalling behaviour. Consider the difference between the following pairs of utterances:

We do not give discounts.

We do not normally give discounts.

We can't accept your position.

We can't accept your position in its present form.

By adding qualifications to your statements, you prepare to move on from the argument step and pave the way for the next step, proposals. Reciprocated signals ensure "safe conduct" for the party making fresh proposals in that they guarantee that the conciliatory nature of the action will not be taken as a surrender. Parties can then make propositions without losing face and without surrendering to the opponent's position.

Signalling behaviour creates the possibility of agreement. From argument, the negotiator has then moved to proposals or the possibility of making proposals.

\subsubsection{Proposing}

A proposition is an offer or a claim which moves from the original position. A proposition beats an argument. It gets things moving. It relieves tension caused by a lack of knowledge of the other party's expectations. The implication of negotiation is that there is the possibility of movement from an opening position, and a proposal is a movement towards, if not into, the bargaining arena. 
When presenting a proposal, a step by step approach is very useful. One way to improve your presentation is to separate the proposal from its explanation and its justification. It is important to present the items of the proposal first and only thereafter to proceed by explaining and/or justifying its content. If these two parts are mixed the support for your proposal can sound rather insignificant, almost like an apology for making it. You run the risk that your opponent may think you have doubts about it and chooses to press you harder to get further concessions. On the other hand, if you postpone your explanations and justifications and present them separately, they gain more emphasis and appear to be stronger and more weighty arguments.

Secondly, it is important not to engage in instant rejection of your opponent's proposal. Even when the proposition is absolutely unacceptable to you, it is best to treat it, and the proposer, with some respect. You will not appear to have considered it seriously if you have rejected it out of hand. As a negotiator, you may intend to reinforce your hard stance, but there are other ways of achieving the same ends which are less likely to antagonize your opponent. He/she (like yourself) would want to have his/her views considered and you are bound to throw points away by bluntly refusing to do so. Instead, you listen carefully to the proposition and ask questions to clarify any points you are not clear on. You can then give a detailed response instead of a flat rejection or an emotional outburst. In case part of the proposal is of interest to you, you can start a negotiation on these points.

One advantage of making proposals is that they change the balance of power. If a negotiator has just made a proposal, he/she gains a strong position because he/she can adopt the attitude: "I have made a proposal!" In doing so, it is possible to pass the responsibility for the next stage firmly to the other side.

\subsubsection{Packaging}

Packaging entails an activity in response to the opening moves that have been made in the negotiation. It aims at facilitating mutual progress from the stage at which the parties stand to a position for which they might settle. A "package" differs from a list of opening demands and offers in that the latter sets out the proposer's originally stated objectives, while the purpose of the former is to introduce revised objectives in response to the opponent's reaction.

A useful strategy is to regard your concessions on the other party's terms. A negotiator can show his/her opponent the consequences of insis- 
ting on a course of action: If so and so, then $\mathrm{X}$ ( $\mathrm{X}$ is bad for the opponent). This can be followed by a package which meets the opponent's interests: On the other hand, if $\mathrm{Y}$, then $\mathrm{Z}$ ( $\mathrm{Z}$ is in the opponent's interest). The following statement is an example of a package: "If you are prepared to pay the higher cost we could achieve the higher specification and meet your delivery deadline" (Kennedy/Benson/McMillan 1983, 82).

Packaging involves actively seeking variables and these are not always obvious. This is one of the reasons why it is so important not to throw concessions away but keep as many options as possible open from the earlier rounds of the negotiation. When presenting a package, it is of great importance to be specific on what concessions would be possible and to state precisely what is wanted in return. In packaging, no free gifts are offered. Telling your opponent what your offer is and being ready to exchange concessions is a strong negotiating platform. It prepares the way for the bargaining step where the actual exchange can take place.

\subsubsection{Bargaining}

Bargaining is the most intensive part of the negotiation process because great attention must be paid to the exchange of concessions. The most important rule for the bargaining step is to make all propositions and concessions conditional. Therefore, the bargaining step has been described as the if - then stage of negotiation. If an if has been placed in front of a statement it protects the negotiator from misappropriation, while without an if it is possible to say "Thank you very much" and pocket the concession without reciprocating. Conditioning your statement is like tying an invisible string to the offered concession which you pull back if your opponent does not agree to your concession.

Inexperienced negotiators often miscalculate their situation and assume that if they are generous their opponents will be generous in return. Many negotiators who recognize the importance of a conditional proposal are often so concerned with getting their revised offer right and with getting it across to their opponent that they "forget" to place conditions upon it.

\subsubsection{Closing and agreeing}

The purpose of closing is to lead to agreement. Negotiators may find it difficult to close, most often because they do not know when to close. The uncertainty arises because neither side is sure when the other party's limit has been reached. The decision to close the bargaining step is a 
matter of judgement.

\section{Communication skills}

\subsection{General vs specific skills}

In addition to the specific skills required in English for Specific Purposes (ESP) (e.g. technical English, legal English, etc.), the importance of general communicative abilities has been widely acknowledged by people in management. When asked to evaluate the relative importance of a specialized technical usage (the professional jargon) in comparison with the non-specialized, conversational uses of the language, European executive managers assessing their foreign language needs gave the following illustrative answers (Beneke 1981, 32-33) (TL = Technical Language):

Beneke points out that the last answer is that of someone working in internal control and accounting. He concludes that, although there is a

Fig. 5

wide difference in the intensity of the use of technical language, depending on the occupational field and the position in the hierarchy, the following trends are quite clear:

1. TL is more important for "technical" professions such as engineers than for people with frequent customer contacts, for example.

2. The higher someone is in the hierarchy, the less important TL is. In the middle ranks TL seems to be most important, typically for 
specialist functions. Management relies on the technical expertise of its respective staff and then enters into negotiations.

3. Customer-oriented language activities require a high degree of social, conversational uses of the language.

In management functions language is crucial to create understanding, to gain confidence, to make oneself socially acceptable to the other, just as it is the medium in which to negotiate, plead, persuade and decide. The functions to be performed in face-to-face interactions are numerous. In the following some aspects likely to cause problems for the non-native negotiator are discussed.

\subsection{Communication difficulties}

A number of factors contribute to making negotiation a situation of stress and pressure which is difficult to handle even for native speakers: The importance of stakes, the constant pressure of time, the need to account for results, the impact on reputation, etc.

The damaging effect of poor handling of communication processes is the subject of Jønsson's (1987) paper. According to him even experienced and otherwise competent negotiators often make a number of mistakes respective to handling a negotiation situation. For example, they often use a mode of "availability heuristics", i.e. they let recent striking events influence their negotiations, and they tend to overemphasize dispositional factors (i.e. personal traits) when interpreting the behaviour of others, whereas when interpreting their own behaviour, they tend to overemphasize situational factors. If a negotiation event is considered to be successful, it is your own merit, if, on the other hand, it is felt to be unsuccessful, this is due either to the other party, or to the "situation", rather than to yourself as a negotiator. There is a tendency to act defensively, to rely on stereotypes, to judge oneself as common and normal, and the other party as deviant. In addition, the negotiator may be too confident in his/her capability of understanding the counterpart, which is likely to lead to a narrow communication pattern lacking exploration of the intentions of the other side.

These difficulties are further increased when the negotiation takes place in settings in which at least one of the participants has to use a foreign language. Psychologists refer to the "role duality" of the speaker, i.e. the additional pressure felt by the negotiator using a foreign language.

When negotiation takes place between two persons with a shared language background, negotiators normally share the same culture and are 
able to use and to interpret to a very high degree the subtleties of that language. If you have to speak a foreign language and are, furthermore, also in a foreign place, you are at a disadvantage already from the outset.

The additional difficulty of having to negotiate in a foreign language adds to the pressure of the situation. Precious time may be wasted in hunting for words, ideas may get lost or lose clarity, and particularly, if your counterpart is speaking his/her mother tongue you are likely to be at a disadvantage (Hansberger 1985). In the following I point to communication difficulties observed in Danish advanced learners of English which are likely to cause problems if these learners are to take part in international negotiations. This information is supplemented by observations made by other researchers when available.

\subsubsection{Taking the initiative/making a close}

In negotiation it is important to know how to use questioning as a powerful persuasive tactic. By asking questions you will give the opponent the opportunity of expanding on his/her qualifications and his/her opposition to what is being discussed. In doing so, you can explore the issues that separate you from your opponent and extract information that can be utilized in formulating a persuasive proposal. Furthermore, the person who asks the questions controls the process of negotiation and thereby accomplishes more in bargaining situations.

However, a discourse analysis employing an extended version of Sinclair/Coulthard's (1975) model shows that advanced Danish learners of English find it difficult to take the initiative in conversations with native speakers. These learners have particularly low scores on initiating (I) discourse acts such as I-inquire and I-propose (Trosborg forthcoming).

A number of studies report on learner difficulties in connection with opening and closing a theme or a conversation, (e.g. Wagner/Petersen 1982, Trosborg 1984, Loercher 1986). Learners employ relatively few initiating and closing moves compared with native speakers of English.

Stalpers/Ulijn (1984), who investigated the problems experienced by Dutchmen negotiating abroad, report that the negotiators they interviewed stated that they often got irritated because they did not know how to close a theme, or even a whole conversation in an acceptable, that is to say a quick, polite and diplomatic way (ibid p. 3).

Leaving to the native speaker to take the initiative in negotiation, to close themes, to finalize agreements, etc. gives him/her a powerful tool to turn the outcome of the negotiation to his/her advantage. It is impor- 
tant, therefore, that learners receive training in mastering these discourse functions. See also Trosborg/McVeigh (1988,13-15) on the use of preclosers.

\subsubsection{Making proposals}

Most real negotiations are argued from a base of incomplete information. A negotiator seldom knows his/her opponent's exact priorities, cost structures, and so on. The ability to make proposals, offers, and counteroffers, hypothesizing and proposing exchanges, etc. are important functions of successful negotiation. The findings of my research on suggestions show that learners make far fewer of these communicative acts than native speakers do, and, in addition, the relevance of their suggestions, proposals, and offers are sometimes questionable.

\subsubsection{Administering arguments}

Research findings (Trosborg 1988) show that even advanced non-native speakers of English have problems in administering their arguments for a strategic purpose. Often they disclose their information too willingly at the beginning of a conversation and forget to keep back points to be brought to bear on the issue in question later in the conversation. Most native speakers, on the other hand, know how to "feel their way forward" and build up argumentation successively.

In business negotiation, a successful negotiator must know how and when to exploit his/her offers, concessions, etc. for a strategic purpose and if possible have a trump card to play at a decisive moment.

The importance of separating an argument from its explanation, justification, has been pointed out (see p. 207). This is yet another skill most non-natives do not seem to master. Advanced non-natives who are capable of taking long turns in conversation feel tempted to present most of their arguments and the available support in one turn, and thus they run out of support in the subsequent negotiation. Most non-natives need training in the strategic skill of knowing when and how to present an argument and in the skill of supporting it to proper effect.

\subsubsection{Omitting blunt rejections}

Saying "No" is not a good basis for negotiation and it seldom pays to engage in instant rejection. As has been pointed out, it is always important to listen attentively to the other side and give constructive responses.

There are several useful ways of rejecting a proposal indirectly. The negotiator can state willingness and good intentions, state reasons, suggest alternatives, etc. (see Trosborg/McVeigh 1988, pp. 38-42). 
Indirect rejection is a very difficult skill to master for non-natives. Instead, learners often engage in instant and repeated direct rejections which are only too likely to antagonize the other side.

\subsubsection{Showing firmness/flexibility}

In negotiation you must endure the pressures created by your opponent, be able to suppress frustration, be patient, calm, controlled, and at the same time be capable of creating pressures, and frustration for your opponent to endure. No doubt, the way in which this is done is decisive for the outcome of a negotiation. The ability to be constructive, persistent, firm, as well as polite, is crucial in successful business negotiation.

Firmness can give you a negotiating platform for later flexibility, but the danger is obvious. The firmer a negotiator is, the higher the chances of failure to agree on anything. Therefore, a mixture of the two is often preferable. For example, a good strategy may be to be firm on generalities but flexible on specifics.

It is important to act consistently. Too often non-natives have to go back on their words (cf. Trosborg 1987). To do so is very face-threatening for the negotiator and creates distrust in his/her partner.

\subsubsection{Conditioning propositions}

Negotiations are only possible when the parties in conflict are willing to move from their stated positions and when that willingness is made evident at some point during the interaction. However, when making concessions, it is important not to give free gifts ("You can't get owt for nowt"). A seller who throws away concessions without getting anything in return is bound to make a bad deal. My research findings show that non-natives, as compared to native speakers, fall short on conditioning their statements. When negotiating an agreement, non-natives are bound to face severe difficulties in managing the bargaining step in negotiation.

\subsubsection{Avoiding conflict}

Conflict ridden language and negative reactions can hardly be avoided in business negotiation. However, the argument step in commercial negotiations tends to be more polite than it is in industrial or political negotiation. Disagreement and tension are delicate areas, and negotiators must be made aware of the need for careful expression.

It is important for a negotiator to be able to manage tactful negotiating functions, e.g. 
how to disagree in a polite manner

how to reject politely

how to present counter-arguments

how to put forward elements of persuasion

how to sustain an argument that meets with opposition

how to win an argument and, at the same time, save the opponent's face

how to make concessions on your own part without losing face

how to use politeness markers (cf. Trosborg 1988, on "downgraders", "sweeteners", and "disarmers").

The negotiator must avoid adopting a threatening attitude ("Judge not that ye be not judged"). Attack leads to counter-attack and a heated argument is likely to follow (Trosborg 1987a). In bilateral "conflict" negotiations (complaints) where a dispute has arisen as a result of the relationship between the two parties: late delivery, poor performance, component failure, etc., knowledge of complaint strategies is useful. In most cases the more severe strategies of direct accusation and blame must be avoided. However, my research findings (ibid) have shown that these strategies are often employed by learners to the exclusion of more indirect strategies when they meet with opposition from their opponents in conflict situations.

\subsubsection{Requesting repair/forbearance}

If a buyer has a complaint serious enough to be made known to his/her supplier, it is worthwhile considering what compensation, etc. would be required. The complainer may not get exactly what he/she demands but will, in most cases, get more than an apology. By requiring of your supplier, by means of a reasonable request for repair, that he/she puts things right, you offer him/her the opportunity of maintaning your goodwill.

When making a request for forbearance, it is advisable not to adopt a threatening attitude. You can ask questions about future procedures, but it would be unwise to threaten to terminate all future orders.

Learners tend to make fewer requests for repair than native speakers, but they issue more threats than native speakers who hardly ever resort to threatening behaviour (cf. Olshtain/Weinbach 1985, Trosborg 1987a).

\subsubsection{Recognizing the opponent's point of view}


In addition to the functions mentioned above, it is also of great importance for a negotiator to be able to recognize his/her opponent's viewpoint, to find common ground, and to cooperate to mutual advantage. It is important to maintain the dialogue and keep up a friendly working atmosphere and relationship. If a negotiator is self-centered, he/she is likely to create a hostile atmosphere and consequently risk the breaking off of all contact. Social adaptability and willingness to listen to your opponent's arguments are important qualifications in negotiation.

When paying attention to what your partner has to say, you are in a good position to negotiate. Furthermore, most people do not like being interrupted and, in doing so, you are likely to create antagonistic feelings. Adversely, you run the risk of killing off the concession that might have been tagged onto your opponent's proposal.

Recognizing your opponent's cultural integrity and respecting a cultural heritage different from your own is also a very helpful and often necessary aspect of negotiation.

\section{Concluding remarks}

Communication skills are a prerequisite for good negotiators and special care should be taken to avoid damaging mistakes. As we have seen, research findings suggest that non-native speakers can be expected to have difficulties in expressing themselves in an optimal way when taking part in international negotiations. The act of negotiation puts pressure on you, and this pressure is definitely increased when you have to negotiate in a foreign language. In situations of conflict the non-native negotiator easily becomes aggressive, he/she may have difficulties in expressing willingness to cooperate and often lacks the communicative skills needed, e.g. to turn down an offer without creating the impression of making a definitive refusal.

The skilled negotiator operating in his/her mother tongue is able to control the situation to a much larger extent. He/she can improvise, rely on gift, flair, habit, experience, etc., he/she controls the language of, e.g. arguing, influencing, adjusting and bargaining and is often able to use the situation to proper advantage, even though the negotiator is unaware of the strategies employed.

Generally speaking, international negotiators know about the problems their non-native speaker counterparts are faced with and act accordingly. They can show openness and tolerance, and the possibility of "softening" the effect of an ill-chosen word or expression through reformulation 
and/or clarifying questions often exists.

As pointed out by Dupont $(1988,7)$ a negotiator will, no doubt, benefit more from a strong bargaining position accompanied by relatively poor communication skills than from efficient communication with the limits of a very weak bargaining posture. It is also clear, though, that in many intermediate situations skill in communication behaviour will be of great benefit to the negotiator in managing the process and in achieving a profitable outcome of the negotiation.

In the long run, poor handling of communication processes will have a bad impact on the partner and may progressively and cumulatively damage the relationship. It may reduce the credibility of the negotiator and impair mutual trust, so that it becomes more difficult, if not impossible, to progress towards an acceptable solution (cf. Dupont 1988, 12). In any case, poor communication handling is likely to slow down the negotiation process and disrupt a smooth progression towards an agreement.

In this connection, the results of a survey conducted among Dutch businessmen (cf. Stalpers/Ulijn 1984, 1) have shown that a lack of knowledge of the language and of the partner often results in ineffective negotiations, and, in the worst cases, it even results in abandoning further negotiation.

As research into the negotiation process has mainly focused on psychological and economic aspects, detailed answers to many questions concerning language use are still lacking. Furthermore, most conclusions so far are based on negotiations in experimental settings. These negotiations may well differ from negotiations in real life settings, just as simulations have a tendency to reinforce cultural stereotypes (Dupont 1988). We must therefore be aware of the danger of relying on this type of data.

An important goal of future research will be to provide data on the strategies employed in real life negotiations involving the linguistic realisation of these strategies subjected to cultural influences. Only when social-psychological research is integrated with the findings of cross-cultural and cross-linguistic research can we arrive at a model of negotiation which shows us how culture influences strategic and linguistic behaviour and ultimately determines negotiation behaviour.

Only a few studies of this kind are in progress. A Dutch research group (cf. Stalpers/Ulijn 1984, Ulijn/Gorter 1987) are in the process of comparing French-French, Dutch-Dutch and French-Dutch negotiations with the aim of arriving at a model of negotiation in linguistic terms which 
would make it possible to identify and explain communication problems arising during intercultural negotiation. Also a Danish study (Firth 1989), in wich non-native speakers are video-taped in actual negotiations, aims at providing knowledge of the linguistic aspects of negotiation. Fant (this volume) and Grindsted (this volume) are concerned with the influence of cultural/affective factors on discourse behaviour in Scandinavian/Spanish negotiations, though with simulations as their data-base.

Videotaped sessions of actual international negotiations would provide, not only knowledge of the realization of relevant language functions, but they would also show how linguistic functions interact with other functions (e.g. non-verbal behaviour) and with decison making processes. Likewise, they would provide a useful basis for analyzing crosslinguistic and cross-cultural breakdowns in communication.

Highlighting the problems of negotiation interactions from a linguistic point of view could contribute to a better understanding of intercultural contact and could result in practical suggestions concerning language courses for specific purposes.

\section{Litteratur}

Beneke, Jürgen (1981): Foreign languages on the top floor: European executive managers evaluate their foreign-language needs. In Reinhold Freudenstein, Jürgen Beneke and Helmut Poenisch (eds.), Language incorporated, Oxford: Pergamon Press, 23-43.

Brislin, R. W. (1981): Cross-cultural encounters. Face-to-face interaction, New York: Pergamon.

Coulthard, M./Montgomery, M./Brazil D. (1981): Developing a description of spoken discourse. In M. Coulthard/M. Montgomery (eds.), Studies in discourse analysis, London: Routledge \& Kegan Paul.

Dupont, Christophe (1988): International negotiations. Communication, language and cross-cultural aspects. Paper presented at 2nd International Eindhoven LSP Conference, 1988.

Firth, Alan (1989): "Orderliness" in cross-cultural communication: Some Preliminary Remarks. ADLA Bulletin.

Graham, John L./Herberger, R. A. (1983): Negotiators abroad - don't shoot from the hip. Harvard Business Review, July-August, 161-168.

Hansberger, Frank O. (1985): Say it: 888 expressions pour négocier en anglais and how to use them. Paris. Mazarine.

Harris, Philip R/Moran, Robert T. (1983): Managing cultural differences, Houston: Gulf Publishing Company.

Janosik, Robert J. (1988): Rethinking the culture - negotiation link. Making deals in strange places. Negotiation Journal. January 1988, Vol. 4, number 1, 5-13. 
Kennedy, Gavin (1985): Negotiate anywhere. London: Business Books.

Kennedy, Gavin/Benson, John/McMillan, John (1981): Managing negotiations. London: Business Books.

Kroeber, A. L. and Kluckholm C. (1982): Culture: a critical review of concepts and definitions. Cambridge. Mass.: Havard University Press.

Lees, Barry (1984): Negotiate in English. London: Longman.

Loercher, W. (1986): Conversational structures in the foreign language classroom. In G. Kasper (ed.), Learning, teaching, and communication in the foreign language classroom. Aarhus: Aarhus University Press.

Moran, Robert T. (1985): Cross-cultural contact. International Management, November.

Pye, Lucian (1982): Chinese commercial negotiating style. Cambridge, Mass.: Oelgeschlager, Gunn \& Hein.

Ricks, David A. (1983): Big business blunders, Illinois: Dow Jones-Irwin.

Samovar, Larry A./Porter, Richard E. (1982): Intercultural Communication: A reader, Belmont: Wadsworth Publishing Company.

Sinclair, J. M./Coulthard, R. M. (1975): Towards an analysis of discourse. The English used by teachers and pupils, London: Oxford University Press.

Stalpers, Judith/Ulijn, Jan M. (1984): Theme transitions in negotiations. Paper presented at AILA, Brussels.

Trosborg, Anna (1984): Stimulating interaction in the foreign language classroom through conversation in small groups of learners. In Singleton, D. M./Little, D. G. (eds.), Language learning in formal and informal contexts. Dublin: Iral.

Trosborg, Anna (1987): Apology strategies in natives/non-natives. Journal of Pragmatics, 1987,147-167.

Trosborg, Anna (1987a) Complaint strategies in natives/non-natives. Paper presented at AILA, Sidney, August.

Trosborg, Anna (1988): Request strategies in natives/non-natives. Paper presented at Second Language Research Forum, Honolulu.

Trosborg, Anna (in preparation): Discourse strategies in natives/non-natives.

Trosborg, Anna/McVeigh, Jean (1988): Rules and roles. A workbook in communication. Herning: Systime.

Ulijn, Jan/Gorter, T. R. (1987): Language, culture and technical-commercial negotiating. In H. Coleman (ed.), Working with language. The Hague: Mouton.

Wagner, Johannes/Petersen, Uwe Helm (1982): Kommunikation i fremmedsprogsundervisningen. København: Gjellerup.

Wagner, Johannes/Petersen, Uwe Helm (1988): Zur Definition von Verhandeln - unter besonderer Berücksichtigung von Geschäftsverhandlungen. Pluradicta 11. 